\title{
Design and synthesis of novel thiadiazole-thiazolone hybrids as potential inhibitors of the human mitotic kinesin Eg5
}

Samukelisiwe Pretty Khathi, ${ }^{\mathrm{a}, 1}$ Balakumar Chandrasekaran, ${ }^{\mathrm{a}, 1}$ Sivanandhan Karunanidhi ${ }^{\mathrm{a}}$ Chuin Lean Tham, ${ }^{\mathrm{b}}$ Frank Kozielski, ${ }^{\mathrm{b}}$ Nisar Sayyad, ${ }^{\mathrm{a}}$ and Rajshekhar Karpoormath ${ }^{\mathrm{a} *}$

a'Discipline of Pharmaceutical Sciences, College of Health Sciences, University of KwaZulu-Natal (UKZN), Westville, Durban 4001, South Africa.

${ }^{\mathrm{b}}$ Department of Pharmaceutical and Biological Chemistry, The School of Pharmacy, University College London, 29-39 Brunswick Square, London WCIN IAX, U.K.

*Corresponding author: karpoormath@ukzn.ac.za (R. Karpoormath)

${ }^{1}$ SP Khathi and B Chandrasekaran contributed equally to this work. 


\begin{abstract}
A novel series of 1,3,4-thiadiazole-thiazolone hybrids 5a-v were designed, synthesized, characterized, and evaluated against the basal and the microtubule (MT)stimulated ATPase activity of Eg5. From the evaluated derivatives, $\mathbf{5 h}$ displayed the highest inhibition with an $\mathrm{IC}_{50}$ value of $13.2 \mu \mathrm{M}$ against the MT-stimulated Eg5 ATPase activity. Similarly, compounds $\mathbf{5 f}$ and $\mathbf{5 i}$ also presented encouraging inhibition with $\mathrm{IC}_{50}$ of $17.2 \mu \mathrm{M}$ and $20.2 \mu \mathrm{M}$, respectively. A brief structure-activity relationship (SAR) analysis indicated that 2-chloro and 4-nitro substituents on the phenyl ring of the thiazolone motif contributed significantly to enzyme inhibition. An in silico molecular docking study using the crystal structure of Eg5 further supported the SAR and reasoned the importance of crucial molecular protein-ligand interactions in influencing the inhibition of the ATPase activity of Eg5. The magnitude of the electron-withdrawing functionalities over the hybrids and the critical molecular interactions contributed towards higher in vitro potency of the compounds. The drug-like properties of the synthesized compounds 5a-v were also calculated based on the Lipinski's rule of five and in silico computation of key pharmacokinetic parameters (ADME). Thus, the present work unveils these hybrid molecules as novel Eg5 inhibitors with promising drug-like properties for future development.
\end{abstract}

\title{
Key words:
}

1,3,4-thiadiazole-thiazolone

MT-stimulated ATPase of Eg5

Hybridization

Knoevenagel condensation

GLIDE

ADME prediction 
Clinically available antimitotic agents such as vinca alkaloids and taxanes bind to MTs/tubulin, reorganize MT dynamics and in turn, activate the spindle checkpoint thereby causing mitotic arrest and apoptotic cell death. ${ }^{1,2}$ Due to toxicological limitations such as neurotoxicity and the development of innate or acquired resistance in tumours, these agents can cause serious drawbacks in current cancer chemotherapy. ${ }^{3}$ On the other hand, agents targeting MT-based motor proteins may overcome such limitations as these proteins are not expressed in the adult central/peripheral nervous system and their inhibition had no marked effect on MTs in non-dividing cells. ${ }^{4}$ The mitotic kinesin Eg5 (also known as Kinesin Spindle Protein, KSP, Kif11, a member of the kinesin-5 family) is one such MT-based motor and represents a potential target for the development of novel anticancer agents. ${ }^{5,6}$

During prophase, Eg5 is involved in major cellular events such as centrosome separation and the generation of a bipolar mitotic spindle. ${ }^{7}$ Inhibition of the functions of Eg5 leads to the formation of monopolar spindles followed by mitotic arrest that may eventually cause cell death in certain tumour cell lines. ${ }^{8}$ Overexpression of Eg5 was observed in a number of solid human tumors including colon, breast, uterus, ovary and lung. ${ }^{9}$ When compared with other antimitotic agents or agents altering MT-based cellular events, Eg5 inhibitors exhibit fewer side effects, although neutropenia is the major adverse effect reported till date. ${ }^{4,10,11}$ These facts motivated many drug discovery scientists to identify novel compounds with an aim to develop potent and effective inhibitors against Eg5.

A variety of structurally diverse Eg5 inhibitors were documented in the literature ${ }^{12}$ and the majority of them exhibit their inhibition through an allosteric mechanism. ${ }^{13} \mathrm{~A}$ handful of small molecules were evaluated as potential anticancer candidates and are now in different phases of clinical trials. In clinical phase-I trials, a couple of Eg5 inhibitors such as ARQ$621^{14}$ (Fig. 1) and 4 SC-205 ${ }^{15}$ (the structure is not disclosed elsewhere) were studied for the treatment of solid metastatic tumours and advanced malignancies (AEGIS), respectively (https://clinicaltrials.gov). Similarly, Ispinesib, ${ }^{16}$ SB-743921, ${ }^{17}$ and AZD-4877 ${ }^{18}$ were evaluated in phase-II clinical studies (Fig. 1) for the treatment of kidney cancer, Hodgkin lymphoma, and bladder cancer, respectively (https://clinicaltrials.gov). Interestingly, the Eg5 inhibitors Litronesib ${ }^{19}$ and Filanesib ${ }^{20}$ were evaluated in clinical trials and both contain the 1,3,4-thiadiazole core moiety in their chemical structures (Fig. 1). Litronesib, an allosteric inhibitor has been assessed for the treatment of breast cancer (phase II trial), whereas filanesib was investigated for the management of multiple myeloma in combination with a 
proteasome inhibitor (carfilzomib) (https://clinicaltrials.gov). Currently, a small number of Eg5 inhibitors are under investigation at different stages of clinical trials (Fig. 1).

[Fig. 1]

1,3,4-Thiadiazole analogues have been reported to exhibit versatile applications in the field of pharmaceuticals, medicinal chemistry, agricultural and material chemistry. ${ }^{21}$ They have shown prominent anticancer, ${ }^{22,23}$ antiviral, ${ }^{24}$ antifungal, ${ }^{25}$ analgesic, ${ }^{26}$ antiinflammatory, ${ }^{27,28}$ anti-parasitic, ${ }^{29}$ anti-tubercular ${ }^{30}$ and antioxidant ${ }^{31}$ activities. Furthermore, 1,3,4-thiadiazoles were reported to play a crucial role in the management of certain central nervous system disorders, such as convulsions and mental depression. ${ }^{32,33}$ In addition, they have also demonstrated profound inhibition of Eg5, ${ }^{34} \mathrm{ALK} 5,{ }^{35}$ focal adhesion kinase and Akt/protein kinase $B^{36,37}$ enzymes. Similarly, thiadiazoles displayed in vitro efficacy in cellbased assays against various cancer cell lines such as human hepatoma (HepG2), human breast (MCF-7), and human lung cancer cells (A549). ${ }^{38}$

Comparably, another pharmaceutically important scaffold is thiazolone and its derivatives are well known for their diverse medicinal properties. ${ }^{39-48}$ In particular, 5arylidene-4-thiazolidinone/thiazolone is one of the pharmacophores present in a number of anticancer compounds, displaying activities against a variety of tumour cell lines, including non-small cell lung cancer (H460), paclitaxel-resistant H460taxR, human colon cancer (HT29) and human breast adenocarcinoma (MDA-MB-231). ${ }^{49,50}$ They have also been proven to be potent inhibitors of cyclin-dependent kinases (CDK-1), ${ }^{51}$ kinesin-13 depolymerase $^{52}$ and other kinase targets. ${ }^{53}$

Rational drug design by molecular hybridization is a valid and promising approach in the design, organic synthesis, and development of novel pharmaceutically significant and therapeutically active heterocyclic compounds. ${ }^{54}$ Several recent literature reports and patents in the field of pharmaceutical and medicinal chemistry demonstrated that this strategy is being adopted successfully in many drug discovery projects. ${ }^{55}$

In light of the highly interesting literature reports with respect to the ongoing clinical evaluation of thiadiazole-based Eg5 inhibitors, and in continuation of our efforts to design and synthesize novel heterocyclic medicinal compounds, ${ }^{25,56-58}$ we herein report the synthesis, spectral characterization, and evaluation of novel thiadiazole-thiazolone (TDT) hybrid compounds as potential inhibitors of the MT-stimulated Eg5 ATPase. The molecular hybridization approach was employed for the design of novel Eg5 inhibitor core moiety (Fig. 
2). To better understand the binding mode of the synthesized compounds (5a-v) and to further support the derived structure-activity relationship (SAR) studies, in silico molecular docking simulations were conducted to identify crucial molecular interactions responsible for the inhibition of Eg5. Moreover, in silico drug-like properties and key pharmacokinetic parameters (ADME) were also computed to determine the propensity of $\mathbf{5 a - v}$ to be drug-like compounds for further development.

[Fig. 2]

The synthesis of a novel series of TDT hybrid compounds (5a-v) was accomplished using multi-step organic synthesis by an efficient synthetic route as illustrated in Scheme 1.

\section{[Scheme 1]}

The starting material 1-(5-amino-2-methyl-2-phenyl-1,3,4-thiadiazol-3(2H)-yl)ethan1-one (1) was synthesized and characterized as per the reported method. ${ }^{34}$ Reaction of $\mathbf{1}$ with chloroacetyl chloride in $\mathrm{N}, \mathrm{N}$-dimethylformamide under basic conditions produced (4-acetyl5-methyl-5-phenyl-4,5-dihydro-1,3,4-thiadiazol-2-yl)glycinoyl chloride (2) in good yield (91\%). The ${ }^{1} \mathrm{H}-\mathrm{NMR}$ spectrum of 2 revealed the disappearance of a broad singlet at $\delta 4.11$ ppm corresponding to the $\mathrm{NH}_{2}$ protons and appearance of two informative singlets at $\delta 9.29$ ppm and $\delta 3.91 \mathrm{ppm}$ attributable to $\mathrm{NH}$ and methylene $\left(\mathrm{CH}_{2}\right)$ protons respectively, confirming the formation of $\mathbf{2}$. The hetero-cyclization of $\mathbf{2}$ with ammonium thiocyanate under reflux conditions quantitatively yielded 2-((4-acetyl-5-methyl-5-phenyl-4,5-dihydro-1,3,4thiadiazol-2-yl)amino)thiazol-4(5H)-one (3). This was confirmed by ${ }^{1} \mathrm{H}-\mathrm{NMR}$, in which singlet signals corresponding to $\mathrm{NH}$ and $\mathrm{CH}_{2}$ protons appeared at $\delta 12.18 \mathrm{ppm}$ and $\delta 4.06$ ppm, respectively. The intermediate $\mathbf{3}$ underwent a Knoevenagel reaction with differently substituted aromatic or heterocyclic aldehydes (4a-v) in the presence of ethanolic solution of sodium hydroxide and yielded corresponding final compounds (5a-v) quantitatively. In the ${ }^{1} \mathrm{H}-\mathrm{NMR}$ of $\mathbf{5 a - v}$, the absence of methylene protons (singlet) in the thiazolone moiety and the appearance of the methine proton $(=\mathrm{CH}-)$ resonating in the range of $\delta 7.72-7.99 \mathrm{ppm}$ along with aromatic protons confirmed the formation of the final compounds. There may be an existence of geometrical isomers $(E$ and $Z$ ) of the target molecules 5a-v. However, the $Z$ conformation of the exocyclic $\mathrm{C}=\mathrm{C}$ double bond was assigned based on ${ }^{1} \mathrm{H}-\mathrm{NMR}$ and reported literature data of the analogues of 1,2,4-thiazolidinediones and 4-thiazolones. ${ }^{59-62}$ Specifically, the appearance of the methine proton in the deshielded region $(>\delta 7.72 \mathrm{ppm})$ adjacent to $\mathrm{C}=\mathrm{O}$ of the thiazolone ring displayed higher chemical shift values than the anticipated values for $E$ isomers $(<\delta 7.5 \mathrm{ppm})$, which generally show lower chemical shift 
values since they appear mostly in the shielded region. ${ }^{63}$ Thus, $Z$ conformation was assigned for all the synthesized final compounds 5a-v. Moreover, the NH proton in 5a-v was observed in the deshielded region $\left({ }^{1} \mathrm{H}-\mathrm{NMR}\right)$ and displayed higher chemical shift values between $\delta$ $13.01 \mathrm{ppm}$ and $\delta 12.56 \mathrm{ppm}$. This clearly indicated that the substitution took place on the $2^{\text {nd }}$ position of the thiazolone moiety rather on the $3^{\text {rd }}$ position. This was further correlated with the lactam proton since an imine proton is generally affected by the shielding effect (about $\delta$ $9.5 \mathrm{ppm}) .{ }^{63}$ These interpretations were further validated by recording their ${ }^{13} \mathrm{C}-\mathrm{NMR}$, wherein the arylidene carbon of 5a-v resonated in the range of $\delta 148.9-158.5 \mathrm{ppm}$ in addition to the observed aromatic carbons evidently confirmed the formation of 5a-v via the Knoevenagel condensation mechanism. In addition, the formation of final derivatives were further confirmed by the high resolution mass spectral data (HR-MS) of some representative compounds, which displayed accurate molecular ion peaks that correlated well with their anticipated molecular weights. The synthetic methods and analytical data of all the compounds together with their anticipated structures are presented in the supporting information.

The synthesized novel hybrid analogues 5a-v were evaluated for their potential inhibitory activity against the basal and the MT-stimulated ATPase of Eg5 using previously reported methods ${ }^{64,65}$ and the assay conditions are mentioned in the supporting information. The inhibitory profiles of $\mathbf{5 a - v}$ showed unusual behavior and there is no characteristic inhibition of the basal Eg5 activity (data not shown). However, all hybrid analogues inhibited the MT-stimulated ATPase activity of Eg5 and the data obtained for 5a-v and K858 (reference standard) are presented in Table 1.

\section{Table 1}

Inhibition of the MT-stimulated ATPase activity of Eg5 by hybrid analogues 5a-v. Racemic K858 served as a control.

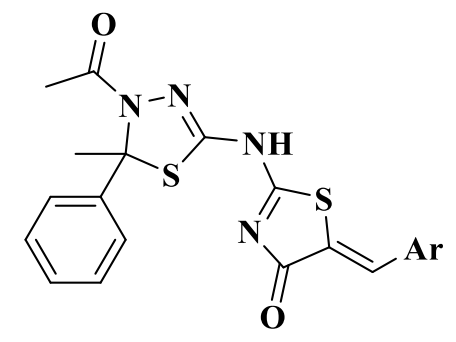




\begin{tabular}{|c|c|}
\hline Compound & $\begin{array}{l}\text { IC }_{50}(\mu \mathrm{M}) \\
\text { MIA }[\%]^{*}\end{array}$ \\
\hline $5 a$ & $\begin{array}{c}62.1 \pm 17.3 \\
(84)\end{array}$ \\
\hline $5 b$ & $\begin{array}{c}42.7 \pm 14.6 \\
(90)\end{array}$ \\
\hline $5 c$ & $\begin{array}{l}\text { Partial inhibition } \\
\text { (50) }\end{array}$ \\
\hline $5 d$ & $\begin{array}{c}71.9 \pm 19.1 \\
(98)\end{array}$ \\
\hline $5 e$ & $\begin{array}{c}39.2 \pm 13.2 \\
\quad(100)\end{array}$ \\
\hline $5 f$ & $\begin{array}{c}17.2 \pm 5.9 \\
(95)\end{array}$ \\
\hline $5 g$ & $\begin{array}{c}63.3 \pm 19.3 \\
(85)\end{array}$ \\
\hline $5 \mathrm{~h}$ & $\begin{array}{l}13.2 \pm 2.3 \\
(90)\end{array}$ \\
\hline $5 \mathrm{i}$ & $\begin{array}{l}20.2 \pm 3.1 \\
\quad(100)\end{array}$ \\
\hline $5 \mathrm{j}$ & $\begin{array}{l}27.5 \pm 7.3 \\
(90)\end{array}$ \\
\hline $5 \mathrm{k}$ & $\begin{array}{c}111.9 \pm 16.1^{* * *} \\
60^{\wedge} \\
(90)\end{array}$ \\
\hline 51 & $\begin{array}{c}252.2 \pm 159.5^{* * *} \\
90^{\wedge} \\
(80)\end{array}$ \\
\hline $5 \mathrm{~m}$ & $\begin{array}{c}128.7 \pm 73.0 \\
(100)\end{array}$ \\
\hline $5 n$ & $\begin{array}{c}330.6 \pm 217.8^{* *} \\
120^{\wedge} \\
(70)\end{array}$ \\
\hline 50 & $\begin{array}{c}47.8 \pm 14.5 \\
(90)\end{array}$ \\
\hline $5 p$ & $\begin{array}{c}132.9 \pm 77.8^{* *} \\
70^{\wedge} \\
(80)\end{array}$ \\
\hline
\end{tabular}




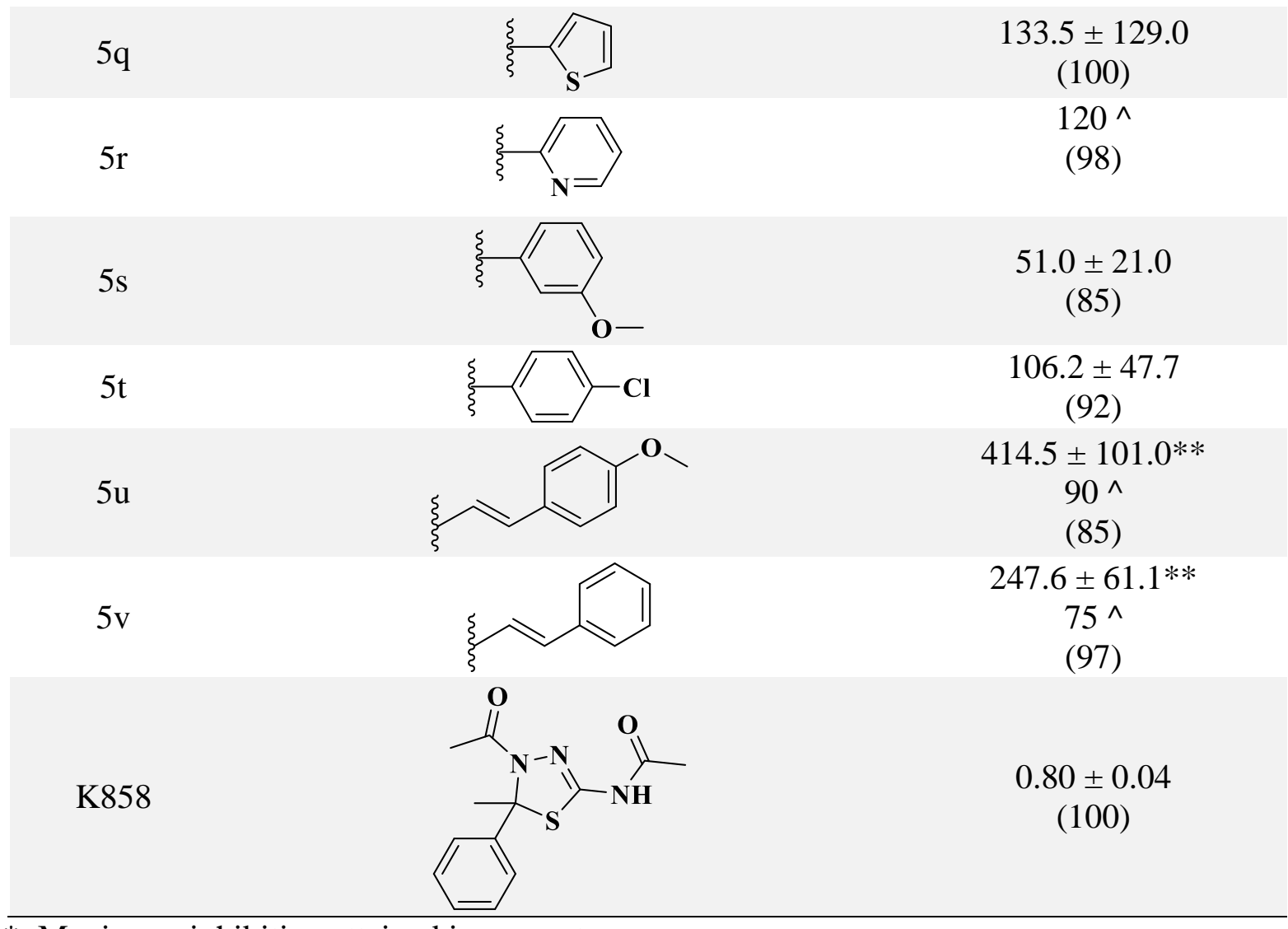

*: Maximum inhibition attained in percentage.

**: $\mathrm{IC}_{50}$ values calculated by Kaleidagraph.

^: $\mathrm{IC}_{50}$ values extracted manually.

Many of the hybrid analogues displayed good to moderate inhibition at the micromolar level for the MT-stimulated Eg5 ATPase activity assay (Table 1). Extracting the $\mathrm{IC}_{50}$ values from hybrid analogues with weak activity resulted in an underestimation. Therefore, the $\mathrm{IC}_{50}$ values of these compounds were also manually extracted from the concentration-response plots (Table 1, supporting information). As the total number of evaluated compounds was quite appreciable, a meaningful SAR was established to identify the more active members from the synthesized series. A positive correlation was observed between the presence of diversified substituents on the aromatic ring of the thiazolone and their inhibitory potential on Eg5 ATPase activity, respectively.

Of the evaluated derivatives, ten compounds showed considerable inhibition of Eg5 ATPase activity with $\mathrm{IC}_{50}$ values ranging from 13.2 to $62.1 \mu \mathrm{M}$. Compounds bearing electron-withdrawing groups such as halogen $(\mathrm{Cl})$, nitro $\left(\mathrm{NO}_{2}\right)$ and weak electron donating groups $\left(\mathrm{OCH}_{3}, \mathrm{OBz}\right)$ on the aromatic ring demonstrated higher inhibition of the MTstimulated ATPase activity of Eg5. Within the halogenated derivatives, chlorine on the $2^{\text {nd }}$ 
position of the aromatic ring (5h) exhibited the most significant inhibition with an $\mathrm{IC}_{50}$ of $13.2 \mu \mathrm{M}$, whereas moderate $\left(\mathrm{IC}_{50}=47.8 \mu \mathrm{M}\right)$, and weak $\left(\mathrm{IC}_{50}=106.2 \mu \mathrm{M}\right)$ inhibition was witnessed when the chlorine was substituted on $3^{\text {rd }}(\mathbf{5 o})$ or $4^{\text {th }}(\mathbf{5 t})$ position of the phenyl ring, respectively. The 4-bromo substituted analogue 5e displayed a moderate (39.2 $\mu \mathrm{M})$ inhibition, while three-fold decreased $(132.9 \mu \mathrm{M})$ activity was observed for fluorine at the $2^{\text {nd }}$ position (5p). The benzyloxy substituted compound $\mathbf{5 f}$ also exhibited significantly higher inhibition with an $\mathrm{IC}_{50}$ of $17.2 \mu \mathrm{M}$.

In comparison with chlorine, an electron-withdrawing nitro substituent also equally contributed to the inhibitory potential of the hybrid analogues. Remarkably, compounds bearing a nitro group at the $4^{\text {th }}(\mathbf{5 i})$ or $3^{\text {rd }}$ position $(\mathbf{5 j})$ of the phenyl ring showed nearly equal IC $_{50}$ values $20.2 \mu \mathrm{M}$ and $27.5 \mu \mathrm{M}$, respectively, indicating that there is no considerable difference in inhibiting ATPase activity of $\mathrm{Eg} 5$ with respect to the position of the nitro substituent on the aromatic ring. A moderate inhibition $\left(\mathrm{IC}_{50}=42.7 \mu \mathrm{M}\right)$ was perceived for the compound bearing a methoxy group on the $4^{\text {th }}$ position $(\mathbf{5 b})$, whereas dimethoxy substitution (5d) resulted in one-fold decrease in the inhibition of MT-stimulated ATPase activity of $\mathrm{Eg} 5\left(\mathrm{IC}_{50}=71.9 \mu \mathrm{M}\right)$. The unsubstituted phenyl (5a) and 4-methyl substituted phenyl (5g) derivatives presented $\mathrm{IC}_{50}$ values $62.1 \mu \mathrm{M}$ and $63.3 \mu \mathrm{M}$, respectively indicating that there is no significant contribution by the weak electron donating methyl group in enhancing the inhibitory profile of the parent 5a. Incorporating an alkene linker $(-\mathrm{C}=\mathrm{C}-)$ between an arylidene carbon and the phenyl substituent yielded the analogue $\mathbf{5 v}$, which demonstrated a substantial decrease in the potency $\left(\mathrm{IC}_{50}=247.6 \mu \mathrm{M}\right)$. This suggested that the additional conjugation did not improve the potency of the analogue.

The presence of two methoxy groups at the $3^{\text {rd }}$ and $4^{\text {th }}$ positions of the phenyl ring in 5k imparted weaker inhibition $\left(\mathrm{IC}_{50}=111.9 \mu \mathrm{M}\right)$, while poor or no inhibition was revealed for 5u. The $N, N$-dimethylamino substituent on the phenyl ring in $\mathbf{5 l}$ demonstrated weaker inhibition $\left(\mathrm{IC}_{50}=252.2 \mu \mathrm{M}\right)$, whereas exocyclic conjugation with additional two carbons $(\mathbf{5 m})$ resulted in one-fold increased potency $\left(\mathrm{IC}_{50}=128.7 \mu \mathrm{M}\right)$ when compared with the former. Bioisosteric replacement of the phenyl ring of $\mathbf{5 a}$ with pyridine (5r) or thiophene $(\mathbf{5 q})$ resulted in nearly two-fold decrease in the inhibition at $120 \mu \mathrm{M}$ and $133.5 \mu \mathrm{M}$, respectively. Replacement with furan (5n) furnished very poor inhibition $\left(\mathrm{IC}_{50}=330.6 \mu \mathrm{M}\right)$ of the MTstimulated Eg5 ATPase activity.

A brief SAR analysis unveiled that the chloro substituent at the $2^{\text {nd }}$ position of the phenyl ring (5h) exhibited higher potency followed by a highly electron-withdrawing nitro 
group at the $4^{\text {th }}$ position of the phenyl ring (5i) of the thiazolone motif (Fig. 3). The presence of electron donating functionalities on the aromatic ring yielded relatively moderate potency. The unsubstituted compounds and analogues bearing bioisosterically-replaced moieties displayed poor inhibition of the MT-stimulated ATPase activity of Eg5.

[Fig. 3]

In order to gain more insight into the binding mode of the new hybrid analogues 5a-v in the allosteric inhibitor binding pocket of Eg5 (formed by helix $\alpha 2$, loop L5 and helix $\alpha 3$ ), and to further support the SAR study, we performed molecular docking simulations using the X-ray crystal structure of Eg5 complexed with a thiophene-containing inhibitor K03 [Protein Data Bank (PDB) ID: 2UYM] ${ }^{66}$ As the hybrid analogues resemble some of the key pharmacophoric features of the bound inhibitor K03, the PDB complex (ID: 2UYM) was selected as a target protein for the molecular docking studies (see supporting information for protocol). Prior to the docking of the synthesized ligands, the protocol was validated by docking a cognate ligand (K03) into the pre-defined binding site of Eg5 model using the Glide module ${ }^{67}$ of Schrodinger-Maestro $11.2^{68}$ with default settings. The docked pose of K03 revealed a similar type of binding orientation and molecular interactions with crucial amino acids of Eg5 as that of the cognate ligand in the PDB structure. Apart from reproducing the reported molecular interactions, the secondary amino group (NH-) of the docked K03 exhibited a weak hydrogen bond (2.56 ̊̊) specifically with the carbonyl oxygen of Glu116 (Fig. 4).

\section{[Fig. 4]}

The most active compound $\mathbf{5 h}$ docked well into the allosteric binding pocket of $\mathrm{Eg} 5$ (PDB ID: 2UYM) and exhibited molecular interactions with crucial amino acids (Fig. 5a). The secondary amino group of $\mathbf{5 h}$ demonstrated a strong hydrogen bond $(1.75 \AA)$ interaction with the carbonyl oxygen of Glu116. Further, the 2-chloro phenyl ring of $\mathbf{5 h}$ exhibited a remarkable $\pi$-cation interaction with the basic residue $\operatorname{Arg} 119$ and showed hydrophobic interactions with residues Trp127, Leu132, and Tyr211. The phenyl ring at the chiral center of the thiadiazole core moiety settled well in the binding pocket surrounded by the side chains of the residues Glu162, Arg221, Tyr231, and Ser237. As expected, no hydrogen bond interactions were observed for the carbonyl oxygen's of $\mathbf{5 h}$ towards any of the active-site residues of Eg5 (Fig. 5a). 
The docked pose of weakly active compound $\mathbf{5} \mathbf{u}$ disclosed a weak hydrogen bonding interaction between $\mathrm{NH}$ - of the ligand and the carbonyl oxygen $(\mathrm{O}=\mathrm{C})$ of Gly117 at a distance of $1.94 \AA$ (Fig. 5b). Also, a $\pi$-cation interaction between the methoxyphenyl ring of 5u and the basic residue Arg221 was observed in the docked pose. The phenyl ring on the chiral carbon of $\mathbf{5} \mathbf{u}$ was encompassed by the active-site residues of Tyr211, Leu214, and Phe239. The methoxyphenyl substitution of $\mathbf{5} \mathbf{u}$ was buried in the cavity formed by amino acids Thr112, Ser232, Phe239, and Asp265 (Fig. 5b).

\section{[Fig. 5]}

From the docking simulations, it was deduced that a hydrogen bond interaction of secondary amino $\mathrm{NH}$ - with the main chain carbonyl oxygen of Glu116 is crucial for the in vitro inhibition of the ATPase activity of Eg5. This crucial interaction was retained in the most active compound $\mathbf{5 h}$, whereas the less active compound $\mathbf{5} \mathbf{u}$ did not preserve this essential hydrogen bond interaction with Glu116. It is also interesting to note that a flipped orientation of the phenyl ring of $\mathbf{5} \mathbf{u}$ was observed due to the presence of an extended conjugation from the thiazolone moiety (Fig. 5b). This flipping pattern in $\mathbf{5 u}$ guided the orientation of the methoxyphenyl ring more towards the acidic amino acids displaying a $\pi$ cation interaction with $\operatorname{Arg} 221$ instead of Arg119 that was observed in the most active compound $\mathbf{5 h}$. Hence, deviation from these essential molecular interactions with crucial amino acids could be the contributing factor for conferring a weaker inhibition for $\mathbf{5 u}$ in the ATPase biological assay.

In order to characterize the drug-likeliness of the hybrid analogues 5a-v, we evaluated these against Lipinski's rule of five in which molecular properties correlated with the oral bioavailability of a drug/drug-like compound. The QikProp of Schrodinger Maestro-11.2 ${ }^{69}$ was used to determine the drug-likeliness (Lipinski's rule of five) and in silico ADME parameters. The results are summarized in Table 2 and demonstrate that all the synthesized hybrids comply with Lipinski's rule of five except $\mathbf{5 e}$, $\mathbf{5 f}$ and $\mathbf{5 m}$, which do not comply with the properties such as molecular weight and/or QPlogP indicating a violation of one or two out of five rules. Generally, ADME (absorption, distribution, metabolism, and excretion) pharmacokinetic properties are crucial for determining the safety and efficacy of drug candidates. Human intestinal absorption (HIA) and Caco-2 permeability (QPPCaco) parameters are good indicators of drug absorption in the intestine and Caco-2 monolayer penetration, respectively. HIA data are the sum of bioavailability and absorption evaluated from the ratio of excretion or cumulative excretion in urine, bile, and feces. ${ }^{70}$ Similarly, the 
QPPCaco permeability parameter is a key feature regulating the drug metabolism and its access to biological membranes. ${ }^{35}$ The predicted percentages of human oral absorption for 5a-v were $80.8 \%$ to $100 \%$ in all cases and QPPCaco values ranged from 92.946 to 968.211 clearly manifested that all the final compounds theoretically infer good oral absorption.

The partition coefficient (QPlogPo/w) and water solubility (QPlogS) are crucial factors involved in the absorption and distribution of the drugs within the human body. For the synthesized molecules 5a-v, QPlogPo/w, and QPlogS values were computed, which ranged from 3.188 to 5.759 and -8.093 to -4.981 , respectively. Further, we predicted the number of violations of Jorgensen's rule of three with the recommended parameters $(\mathrm{QP} \log \mathrm{S}>-5.7$, QPPCaco $>22 \mathrm{~nm} / \mathrm{s}$, primary metabolites $<7) .{ }^{71}$ With the exception of $\mathbf{5 n}$ and $\mathbf{5 r}$, most of the compounds deviated by a maximum of one parameter out of three. Thus, the QikProp predicted the physico-chemically significant descriptors and pharmaceutically relevant properties, all of which establish that 5a-v seem to have good drug-like properties (Table 2 and footnote) and may serve as a starting point for the synthesis of more active analogues.

We herein reported the synthesis, spectral characterization of differently substituted TDT hybrids 5a-v and identified novel compounds some of which exhibiting good inhibition of the MT-stimulated ATPase activity of Eg5. The SAR study denoted that the significance of chlorine and electron-withdrawing substituents on the phenyl ring of the thiazolone motif in acquiring higher inhibition of the enzymatic activity, whereas the substitutions with electron-donating groups exhibited moderate inhibition. In particular, compound $\mathbf{5 h}$ was found to be the most promising lead molecule exhibiting an $\mathrm{IC}_{50}$ of $13.2 \mu \mathrm{M}$ against the MTstimulated Eg5 ATPase activity. Moreover, compounds $\mathbf{5 f}$ and 5i also demonstrated comparatively good inhibition as that of $\mathbf{5 h}$. In silico docking studies of the synthesized compounds with the X-ray crystal structure of Eg5 demonstrated the significance of a hydrogen bond interaction with the side chain of Glu116 and conservation of the distinct binding orientation in acquiring potential inhibition for $\mathbf{5 h}$ in vitro. These encouraging SAR study followed by molecular docking analyses propounded that $\mathbf{5 h}$ could be a good starting point towards the design of novel and more potent Eg5 inhibitors. In silico prediction of druglikeliness and ADME parameters suggested that several of our analogues have promising drug-like properties indicating further potential for drug development. Currently, lead optimization and further syntheses of novel analogues bearing different substitutions on the chiral center to obtain more potent Eg5 inhibitors are in progress. We trust that our research findings could contribute effectively and positively toward the discovery of new 1,3,4thiadiazole scaffold based Eg5 inhibitors as potential anticancer agents with favourable druglike properties. 
Table 2

The drug likeliness and in silico ADME properties of synthesized hybrid analogues 5a-v calculated using QikProp.

\begin{tabular}{|c|c|c|c|c|c|c|c|c|c|c|c|c|}
\hline \multirow[t]{2}{*}{ Entry } & \multicolumn{5}{|c|}{ Drug likeliness (Lipinski's rule of five) } & \multicolumn{7}{|c|}{ In silico ADME by QikProp } \\
\hline & $\begin{array}{l}\text { Molecular } \\
\text { weight }\end{array}$ & $\begin{array}{l}\text { QPlogP } \\
\text { O/W }\end{array}$ & $\begin{array}{l}\text { H- } \\
\text { bond } \\
\text { donor }\end{array}$ & $\begin{array}{l}\text { H-bond } \\
\text { acceptor }\end{array}$ & $\begin{array}{l}\text { Violation of } \\
\text { Lipinski's } \\
\text { rule }\end{array}$ & $\mathbf{Q P l o g S}^{\mathrm{b}}$ & QPlogHERG $^{\mathrm{c}}$ & QPPCaco $^{\text {d }}$ & QPPMDCK $^{\mathrm{e}}$ & QPlogKhsa $^{f}$ & $\begin{array}{l}\text { \% human } \\
\text { oral } \\
\text { absorptiong }\end{array}$ & $\begin{array}{l}\text { Violation } \\
\text { of rule of } \\
\text { three }\end{array}$ \\
\hline $5 \mathbf{a}$ & 422.519 & 3.891 & 1 & 7.50 & 0 & -5.864 & -6.623 & 916.992 & 992.873 & 0.342 & 100 & 1 \\
\hline $5 \mathbf{b}$ & 452.545 & 3.927 & 1 & 8.25 & 0 & -5.978 & -6.465 & 905.090 & 981.113 & 0.322 & 100 & 1 \\
\hline $5 c$ & 467.516 & 3.270 & 1 & 8.50 & 0 & -5.937 & -6.501 & 125.105 & 115.654 & 0.298 & 83.6 & 1 \\
\hline 5d & 482.571 & 4.011 & 1 & 9.00 & 0 & -5.948 & -6.255 & 968.211 & 1032.439 & 0.308 & 100 & 1 \\
\hline $5 e$ & 501.415 & 4.459 & 1 & 7.50 & 1 & -6.720 & -6.560 & 905.090 & 2602.580 & 0.480 & 93.0 & 1 \\
\hline $5 f$ & 528.643 & 5.759 & 1 & 8.25 & 2 & -8.093 & -8.118 & 914.792 & 1000.235 & 0.901 & 87.7 & 1 \\
\hline $5 g$ & 436.546 & 4.191 & 1 & 7.50 & 0 & -6.425 & -6.525 & 905.090 & 981.105 & 0.495 & 100 & 1 \\
\hline $5 \mathrm{~h}$ & 456.964 & 4.319 & 1 & 7.50 & 0 & -6.749 & -6.518 & 905.833 & 2142.073 & 0.442 & 100 & 1 \\
\hline $5 \mathbf{i}$ & 467.516 & 3.188 & 1 & 8.50 & 0 & -6.553 & -6.591 & 92.946 & 83.865 & 0.305 & 80.8 & 1 \\
\hline $5 \mathbf{j}$ & 467.516 & 3.195 & 1 & 8.50 & 0 & -6.075 & -6.575 & 97.448 & 86.006 & 0.305 & 81.2 & 1 \\
\hline $5 \mathbf{k}$ & 482.571 & 3.908 & 1 & 9.00 & 0 & -5.944 & -6.283 & 916.992 & 921.033 & 0.282 & 100 & 1 \\
\hline 51 & 465.587 & 4.223 & 1 & 8.50 & 0 & -6.650 & -6.701 & 770.211 & 592.801 & 0.503 & 100 & 1 \\
\hline $5 \mathrm{~m}$ & 491.625 & 5.134 & 1 & 8.50 & 1 & -7.587 & -7.188 & 926.505 & 1102.894 & 0.705 & 100 & 1 \\
\hline $5 n$ & 412.480 & 3.200 & 1 & 8.00 & 0 & -4.981 & -6.112 & 926.505 & 1027.827 & 0.062 & 100 & 0 \\
\hline 50 & 456.964 & 4.376 & 1 & 7.50 & 0 & -6.574 & -6.521 & 926.505 & 2442.855 & 0.453 & 100 & 1 \\
\hline $5 p$ & 440.509 & 4.091 & 1 & 7.50 & 0 & -6.163 & -6.508 & 905.090 & 1611.434 & 0.379 & 100 & 1 \\
\hline $5 q$ & 428.541 & 3.832 & 1 & 7.50 & 0 & -5.841 & -6.251 & 916.992 & 1880.843 & 0.268 & 100 & 1 \\
\hline $5 r$ & 423.507 & 3.321 & 1 & 8.50 & 0 & -5.422 & -6.534 & 728.176 & 796.853 & 0.110 & 100 & 0 \\
\hline $5 s$ & 452.545 & 3.924 & 1 & 8.25 & 0 & -5.958 & -6.457 & 926.505 & 1004.805 & 0.318 & 100 & 1 \\
\hline $5 t$ & 456.964 & 4.383 & 1 & 7.50 & 0 & -6.607 & -6.534 & 905.090 & 2420.576 & 0.457 & 100 & 1 \\
\hline $5 u$ & 448.557 & 4.609 & 1 & 7.50 & 0 & -6.596 & -7.141 & 926.505 & 1102.894 & 0.523 & 100 & 1 \\
\hline $5 v$ & 478.583 & 4.643 & 1 & 8.25 & 0 & -6.707 & -6.975 & 916.992 & 1089.749 & 0.502 & 100 & 1 \\
\hline
\end{tabular}

aPredictedoctanol/water partition co-efficient $\log \mathrm{p}$ (acceptable range from -2.0 to 6.5).

bredicted aqueous solubility in mol/L (acceptable range: -6.5 to 0.5 ).

'Predicted $\mathrm{IC}_{50}$ value for blockage of HERG K+ channels (concern below -5.0 ).

dPredicted Caco-2 cell permeability in $\mathrm{nm} / \mathrm{s}$ (acceptable range: $<25$ is poor and $>500$ is good).

ePredicted apparent MDCK cell permeability in $\mathrm{nm} / \mathrm{s}$ (acceptable range: $<25$ is poor and $>500$ is good).

fPrediction of binding to human serum albumin (acceptable range: -1.5 to 1.5 ).

gPercentage of human oral absorption ( $<25 \%$ is poor and $>80 \%$ is high). 


\section{Disclosure statement}

Authors hereby declare that there are no financial/commercial conflicts of interest.

\section{Acknowledgements}

Authors are grateful to Discipline of Pharmaceutical Sciences, College of Health Sciences, University of KwaZulu-Natal (UKZN), Durban, South Africa for providing access to necessary facilities. Authors (SPK and BC) gratefully acknowledge National Research Foundation (NRF), South Africa for research funding in the form of NRF-Masters Fellowship and NRF-Innovation Post-Doctoral Research Fellowship (Grant No. 99546), respectively. RK is also thankful to NRF-SA for funding this project (Grant No. 103728 and 112079). Authors also sincerely thank Centre for High Performance Computing (CHPC), Cape Town, South Africa for computational resources. Authors express heartfelt thanks to Mr. Dilip Jagjivan and Dr. Caryl Janse Van Rensburg (UKZN, South Africa) for their assistance in NMR and HR-MS experiments.

\section{References}

1. Jordan MA, Wilson L. Microtubules as a target for anticancer drugs. Nat Rev Cancer 2004;4:253-265.

2. Stanton RA, Gernert KM, Nettles JH, Aneja R. Drugs that target dynamic microtubules: A new molecular perspective. Med Res Rev. 2011;31:443-481.

3. Rowinsky EK, Chaudhry V, Cornblath DR, Donehower RC. Neurotoxicity of Taxol. J Natl Cancer Institute Monogr. 1993;15:107-115.

4. Sakowicz R, Finer JT, Beraud C, et al. Antitumor activity of a kinesin inhibitor. Cancer Res. 2004;64:3276-3280.

5. Miki H, Okada Y, Hirokawa N. Analysis of the kinesin superfamily: Insights into structure and function. Trends Cell Biol. 2005;15:467-476.

6. Sarli V, Giannis A. Targeting the kinesin spindle protein: Basic principles and clinical implications. Clin Cancer Res. 2008;14:7583-7587.

7. Hirokawa N. Kinesin and dynein superfamily proteins and the mechanism of organelle transport. Science 1998;279:519-526.

8. Goodson HV, Kang SJ, Endow SA. Molecular phylogeny of the kinesin family of microtubule motor proteins. J Cell Sci. 1994;107:1875-1884.

9. Zhu L, Xiao F, Yu Y, et al. KSP inhibitor SB743921 inhibits growth and induces apoptosis of breast cancer cells by regulating p53, Bcl-2, and DTL. Anticancer Drugs 2016;27:863-872.

10. Compton DA. Spindle assembly in animal cells. Anпu Rev Biochem. 2000;69:95-114.

11. Song H, Zhou S, Wang R, Li S. Kinesin spindle protein (KSP) inhibitors in combination with 
chemotherapeutic agents for cancer therapy. ChemMedChem. 2013;8:1736-1749.

12. Myers SM, Collins I. Recent findings and future directions for interpolar mitotic kinesin inhibitors in cancer therapy. Future Med Chem. 2016;8:463-489.

13. El-Nassan HB. Advances in the discovery of kinesin spindle protein (Eg5) inhibitors as antitumor agents. Eur J Med Chem. 2013;62:614-631.

14. Rosen L, Chen L-C, Iyengar T, et al. Abstract 2750: ARQ 621, a novel potent and selective inhibitor of Eg5: Preclinical data and early results from a clinical phase 1 study. Cancer Res. 2014;70:2750LP.

15. Mross KB, Scharr D, Richly H, et al. First-in-human study of 4SC-205 (AEGIS), a novel oral inhibitor of Eg5 kinesin spindle protein. J Clin Oncol. 2014;32: 2564.

16. Lee CW, Belanger K, Rao SC, et al. A phase II study of ispinesib (SB-715992) in patients with metastatic or recurrent malignant melanoma: A national cancer institute of canada clinical trials group trial. Invest New Drugs. 2008;26:249-255.

17. Holen KD, Belani CP, Wilding G, et al. A first in human study of SB-743921, A kinesin spindle protein inhibitor, to determine pharmacokinetics, biologic effects and establish a recommended phase II dose. Cancer Chemother Pharmacol. 2011;67:447-454.

18. Theoclitou M-E, Aquila B, Block MH, et al. Discovery of (+)-N-(3-Aminopropyl)-N-[1-(5benzyl-3-methyl-4-oxo-[1,2]thiazolo[5,4-d]pyrimidin-6-yl)-2-methylpropyl]-4-methyl-

benzamide (AZD4877), a kinesin spindle protein inhibitor and potential anticancer agent. $J$ Med Chem. 2011;54:6734-6750.

19. Wakui H, Yamamoto N, Kitazono S, et al. A phase 1 and dose-finding study of LY2523355 (litronesib), an Eg5 inhibitor, in Japanese patients with advanced solid tumors. Cancer Chemother Pharmacol. 2014;74:15-23.

20. Woessner R, Tunquist B, Lemieux C, et al. ARRY-520, a novel KSP inhibitor with potent activity in hematological and taxane-resistant tumor models. Anticancer Res. 2009;29:43734380.

21. Hu Y, Li CY, Wang XM, Yang YH, Zhu HL. 1,3,4-Thiadiazole: Synthesis, reactions, and applications in medicinal, agricultural, and materials chemistry. Chem Rev. 2014;114:55725610.

22. Foda HD, Zucker S. Matrix metalloproteinases in cancer invasion, metastasis and angiogenesis. Drug Discov Today 2001;6:478-482.

23. Rzeski W, Matysiak J, Kandefer-Szerszeń M. Anticancer, neuroprotective activities and computational studies of 2-amino-1,3,4-thiadiazole based compound. Bioorg Med Chem. 2007;15:3201-3207.

24. Al-Soud YA, Al-Masoudi NA, Loddo R, La Colla P. In-Vitro anti-HIV and antitumor activity of new 3,6-disubstituted $[1,2,4]$ triazolo[3,4-b][1,3,4]thiadiazoles and thiadiazine analogues. Arch Pharm (Weinheim). 2008;341:365-369. 
25. Karpoormath R, Palkar MB, Patel HM, et al. Novel imidazo[2,1-b]-1,3,4-thiadiazoles as promising antifungal agents against clinical isolate of Cryptococcus neoformans. Eur J Med Chem. 2015;95:514-525.

26. Özadalı K, Özkanlı F, Jain S, Rao PPN, Velázquez-Martínez CA. Synthesis and biological evaluation of isoxazolo[4,5- $d$ ]pyridazin-4-(5H)-one analogues as potent anti-inflammatory agents. Bioorg Med Chem. 2012;20:2912-2922.

27. Gadad AK, Palkar MB, Anand K, Noolvi MN, Boreddy TS, Wagwade J. Synthesis and biological evaluation of 2-trifluoromethyl/sulfonamido-5,6-diaryl substituted imidazo[2,1-b]1,3,4-thiadiazoles: A novel class of cyclooxygenase-2 inhibitors. Bioorg Med Chem. 2008;16: 276-283.

28. Kumar H, Javed SA, Khan SA, Amir M. 1,3,4-Oxadiazole/thiadiazole and 1,2,4-triazole derivatives of biphenyl-4-yloxy acetic acid: Synthesis and preliminary evaluation of biological properties. Eur J Med Chem. 2008;43:2688-2698.

29. Carvalho SA, Lopes FAS, Salomão K, et al. Studies toward the structural optimization of new brazilizone-related trypanocidal 1,3,4-thiadiazole-2-arylhydrazone derivatives. Bioorg Med Chem. 2008;16:413-421.

30. Oruç EE, Rollas S, Kandemirli F, Shvets N, Dimoglo AS. 1,3,4-Thiadiazole derivatives. Synthesis, structure elucidation, and structure-antituberculosis activity relationship investigation. J Med Chem. 2004;47:6760-6767.

31. Padmavathi V, Reddy SN, Reddy GD, Padmaja A. Synthesis and bioassay of aminosulfonyl1,3,4-oxadiazoles and their interconversion to 1,3,4-thiadiazoles. Eur J Med Chem. 2010;45: 4246-4251.

32. Ilies MA, Masereel B, Rolin S, et al. Carbonic anhydrase inhibitors: Aromatic and heterocyclic sulfonamides incorporating adamantyl moieties with strong anticonvulsant activity. Bioorg Med Chem. 2004;12:2717-2726.

33. Jubie S, Ramesh PN, Dhanabal P, Kalirajan R, Muruganantham N, Shanish Antony A. Synthesis, antidepressant and antimicrobial activities of some novel stearic acid analogues. Eur J Med Chem. 2012;54:931-935.

34. Yamamoto J, Amishiro N, Kato K, et al. Synthetic studies on mitotic kinesin Eg5 inhibitors: Synthesis and structure-activity relationships of novel 2,4,5-substituted-1,3,4-thiadiazoline derivatives. Bioorg Med Chem Lett. 2014;24:3961-3963.

35. Patel HM, Sing B, Bhardwaj V, et al. Design, synthesis and evaluation of small molecule imidazo[2,1- $b][1,3,4]$ thiadiazoles as inhibitors of transforming growth factor- $\beta$ type-I receptor kinase (ALK5). Eur J Med Chem. 2015;93:599-613.

36. Sun J, Yang Y-S, Li W, et al. Synthesis, biological evaluation and molecular docking studies of 1,3,4-thiadiazole derivatives containing 1,4-benzodioxan as potential antitumor agents. Bioorg Med Chem Lett. 2011;21:6116-6121. 
37. Chou JY, Lai SY, Pan SL, Jow GM, Chern JW, Guh JH. Investigation of anticancer mechanism of thiadiazole-based compound in human non-small cell lung cancer A549 cells. Biochem Pharmacol. 2003;66:115-124.

38. Dawood KM, Eldebss TMA, El-Zahabi HSA, Yousef MH, Metz P. Synthesis of some new pyrazole-based 1,3-thiazoles and 1,3,4-thiadiazoles as anticancer agents. Eur J Med Chem. 2013;70:740-749.

39. Vicini P, Geronikaki A, Anastasia K, Incerti M, Zani F. Synthesis and antimicrobial activity of novel 2-thiazolylimino-5-arylidene-4-thiazolidinones. Bioorg Med Chem. 2006;14:3859-3864.

40. Vicini P, Geronikaki A, Incerti M, Zani F, Dearden J, Hewitt M. 2-Heteroarylimino-5benzylidene-4-thiazolidinones analogues of 2-thiazolylimino-5-benzylidene-4-thiazolidinones with antimicrobial activity: Synthesis and structure-activity relationship. Bioorg Med Chem. 2008;16:3714-3724.

41. Geronikaki AA, Lagunin AA, Hadjipavlou-Litina DI, et al. Computer-aided discovery of antiinflammatory thiazolidinones with dual cyclooxygenase/lipoxygenase inhibition. J Med Chem. 2008;51:1601-1609.

42. Luo Y, Ma L, Zheng H, et al. Discovery of (Z)-5-(4-methoxybenzylidene)thiazolidine-2,4dione, a readily available and orally active glitazone for the treatment of concanavalin Ainduced acute liver injury of BALB/c mice. J Med Chem. 2010;53:273-281.

43. Deep A, Jain S, Sharma PC, Phogat P, Malhotra M. Synthesis of 2-(aryl)-5-(arylidene)-4thiazolidinone derivatives with potential analgesic and anti-inflammatory activity. Med Chem Res. 2012;21:1652-1659.

44. Küçükgüzel I, Satilmiş G, Gurukumar KR, et al. 2-Heteroarylimino-5-arylidene-4thiazolidinones as a new class of non-nucleoside inhibitors of HCV NS5B polymerase. Eur J Med Chem. 2013;69:931-941.

45. Talje L, Ben El Kadhi K, Atchia K, Tremblay-Boudreault T, Carreno S, Kwok BH. DHTP is an allosteric inhibitor of the kinesin-13 family of microtubule depolymerases. FEBS Lett. 2014;588:2315-2320.

46. Ottanà R, Maccari R, Mortier $\mathrm{J}$, et al. Synthesis, biological activity and structure-activity relationships of new benzoic acid-based protein tyrosine phosphatase inhibitors endowed with insulinomimetic effects in mouse C2C12 skeletal muscle cells. Eur J Med Chem. 2014;71:112127.

47. Tripathi AC, Gupta SJ, Fatima GN, Sonar PK, Verma A, Saraf SK. 4-Thiazolidinones: The advances continue. Eur J Med Chem. 2014;72:52-77.

48. Abdelazeem AH, Salama SA, Maghrabi IA. Design, synthesis, and anti-inflammatory evaluation of novel diphenylthiazole-thiazolidinone hybrids. Arch Pharm. 2015; 348:518-530.

49. Ottanà $\mathrm{R}$, Carotti $\mathrm{S}$, Maccari $\mathrm{R}$, et al. In vitro antiproliferative activity against human colon cancer cell lines of representative 4-thiazolidinones. Part I. Bioorg Med Chem Lett. 2005;15: 
3930-3933.

50. Zhou H, Wu S, Zhai S, et al. Design, Synthesis, cytoselective toxicity, structure-activity relationships, and pharmacophore of thiazolidinone derivatives targeting drug-resistant lung cancer cells. J Med Chem. 2008;51:1242-1251.

51. Chen S, Chen L, Le NT, et al. Synthesis and activity of quinolinyl-methylene-thiazolinones as potent and selective cyclin-dependent kinase 1 inhibitors. Bioorg Med Chem Lett. 2007;17: 2134-2138.

52. Talje L, Ben El Kadhi K, Atchia K, Tremblay-Boudreault T, Carreno S, Kwok BH. DHTP is an allosteric inhibitor of the kinesin-13 family of microtubule depolymerases. FEBS Lett. 2014;588:2315-2320.

53. Lv P-C, Zhou C-F, Chen J, et al. Design, synthesis and biological evaluation of thiazolidinone derivatives as potential EGFR and HER-2 kinase inhibitors. Bioorg Med Chem. 2010;18:314319.

54. Claudio Viegas-Junior, Eliezer J. Barreiro, Carlos Alberto Manssour Fraga. Molecular hybridization: A useful tool in the design of new drug prototypes. Curr Med Chem. 2007;14: 1829-1852.

55. Dias KST, Viegas C. Multi-target directed drugs: A modern approach for design of new drugs for the treatment of alzheimer's disease. Curr Neuropharmacol. 2014;12:239-255.

56. Balakumar C, Ramesh M, Tham CL, et al. Ligand and structure based in silico studies to identify kinesin spindle protein (KSP) inhibitors as potential anticancer agents. J Biomol Struct Dyn. October 2017:1-77.

57. Hampannavar GA, Karpoormath R, Palkar MB, Shaikh MS, Chandrasekaran B. Dehydrozingerone Inspired Styryl Hydrazine Thiazole Hybrids as Promising Class of Antimycobacterial Agents. ACS Med Chem Lett. 2016;7:686-691.

58. Shaikh MS, Palkar MB, Patel HM, et al. Design and synthesis of novel carbazolo-thiazoles as potential anti-mycobacterial agents using a molecular hybridization approach. RSC Adv. 2014; 4:62308-62320.

59. Ottanà R, Maccari R, Barreca ML, et al. 5-Arylidene-2-imino-4-thiazolidinones: Design and synthesis of novel anti-inflammatory agents. Bioorg Med Chem. 2005;13:4243-4252.

60. Vicini P, Geronikaki A, Anastasia K, Incerti M, Zani F. Synthesis and antimicrobial activity of novel 2-thiazolylimino-5-arylidene-4-thiazolidinones. Bioorg Med Chem. 2006;14:3859-3864.

61. Bruno G, Costantino L, Curinga $\mathrm{C}$, et al. Synthesis and aldose reductase inhibitory activity of 5-arylidene-2,4-thiazolidinediones. Bioorg Med Chem. 2002;10:1077-1084.

62. Geronikaki AA, Lagunin AA, Hadjipavlou-Litina DI, et al. Computer-aided discovery of antiinflammatory thiazolidinones with dual cyclooxygenase/lipoxygenase inhibition. J Med Chem. 2008;51:1601-1609.

63. Momose Y, Meguro K, Ikeda H, Hatanaka C, Oi S, Sohda T. Studies on antidiabetic agents. X. 
Synthesis and biological activities of pioglitazone and related compounds. Chem Pharm Bull. 1991;39:1440-1445.

64. Nagarajan S, Skoufias DA, Kozielski F, Pae AN. Receptor-ligand interaction-based virtual screening for novel Eg5/kinesin spindle protein inhibitors. J Med Chem. 2012;55:2561-2573.

65. Talapatra SK, Anthony NG, Mackay SP, Kozielski F. Mitotic kinesin Eg5 overcomes inhibition to the phase I/II clinical candidate SB743921 by an allosteric resistance mechanism. J Med Chem. 2013;56:6317-6329.

66. Pinkerton AB, Lee TT, Hoffman TZ, et al. Synthesis and SAR of thiophene containing kinesin spindle protein (KSP) inhibitors. Bioorg. Med Chem Lett. 2007;17:3562-3569.

67. Friesner RA, Murphy RB, Repasky MP, et al. Extra precision glide: Docking and scoring incorporating a model of hydrophobic enclosure for protein-ligand complexes. J Med Chem. 2006;49:6177-6196.

68. Schrödinger Release 2017-2: Glide, Schrödinger, LLC, New York, NY 2017.

69. Schrödinger Release 2017-2: QikProp, Schrödinger, LLC, New York, NY 2017.

70. Zhao YH, Le J, Abraham MH, et al. Evaluation of human intestinal absorption data and subsequent derivation of a quantitative structure - activity relationship (QSAR) with the Abraham descriptors. J Pharm Sci. 2001;90:749-784.

71. Ntie-Kang F. An in silico evaluation of the ADMET profile of the StreptomeDB database. Springerplus 2013;2:353. 